\title{
The Balcony Party - \\ Mitigation of social isolation \\ during the coronavirus outbreak
}

Hila Z. Gvirts Problovski ${ }^{1}$, Mor Sherman ${ }^{1}$, Victoria Melnikova $^{1}$

${ }^{1}$ Department of Behavioral Sciences and Psychology, Ariel University

Correspondence: hilag@ariel.ac.il (H.Z. Gvirts Probolovski)

Permanent address: Ramat HaGolan St 65, Ariel 


\begin{abstract}
With the ongoing COVID-19 pandemic, there is a growing need for assessing the psychological costs of social isolation (SI). We examine whether the balcony party can help people cope better with SI during the COVID-19 outbreak. We examined the psychological effects of SI on persons in Israel and Italy between March 23th, 2020 and
\end{abstract} April 2th, 2020. A total of 303 quarantined persons responded to a Web-based survey. We found that the effect of balcony parties on the psychological costs of SI is dependent on the level of social isolation. Those who experienced high levels of SI perceived the balcony parties as more beneficial in inducing positive affect and reducing negative affect in comparison to those who experienced low levels of SI. The opposite pattern was observed when individuals were asked about their participation in these parties: individuals with high levels of SI experienced balcony parties as less beneficial than similar pre-outbreak gathering events, while individuals with low levels of social isolation showed an opposite pattern. Finally, for those with high SI, balcony parties did not meet the expectation of creating feelings of communal solidarity. However, a discrepancy between high SI expectations and experience was not found for those with low SI. Our findings demonstrate that the balcony parties are beneficial in reducing the emotional cost of social isolation - but only for those who feel low levels of SI. The fact that individuals with high levels of SI expected more out of these parties suggests the need to develop interventions aimed at optimizing their expectations. As society 
enters a new period in which the costs of social distancing may be higher, our findings are valuable for understanding the psychological battle that individuals face while in social isolation.

Key words: Social Isolation, Social alignment, COVID-19 


\section{Introduction}

In December 2019, the first case of the novel Coronavirus (also known as COVID-19) was reported in Wuhan, China. Since then, the virus has been spread rapidly throughout Asia, Europe, the Middle East, and the Americas. On March 11 2020, it was declared a global pandemic by the World Health Organization (1). Currently, no vaccine exists for treatment of the virus. As a result, health professionals have prescribed social distancing and quarantine as means to reduce viral spreading (2). Social distancing refers to efforts to minimize close interpersonal interactions in public. As individuals may be contagious and unidentified as virus carriers, social distancing reduces the risk of virus transmission (3). Quarantine can be defined as movement restriction of persons who presumed to have been exposed to a contagious disease (4). In battling COVID-19, many countries used social distancing and quarantine to impose major movement restrictions on large populations in specific at-risk zones.

However, the emotional and psychological costs of social distancing and quarantine should be weighed against their obvious public health benefits. Indeed, the emotional and psychological impact of COVID-19 is still largely unknown.

A recent review points to a series psychological hardships both during and after imposition of quarantine in previous disease outbreaks (5). The authors conclude that people under quarantined generally reported high prevalence of psychological distress symptoms. In addition, longer durations of quarantine were associated with poorer 
mental health. Wang et al. (6) surveyed the situation in China during the first two weeks of the COVID-19 outbreak. They showed that even at this very early stage of the outbreak respondents rated the psychological impact as moderate-to-severe. Notably, the ripple effects of the quarantine strategy included exacerbation of social isolation and loneliness. Loneliness can be defined as distress resulting from the perception that one's social relationships are quantitatively less than desirable (7-9). Social isolation refers to an objective lack of interpersonal interactions or engagement with one's community (10). The notion that social isolation leads to loneliness has gained support from studies that found a positive association between low frequency of social contact and loneliness $(11,12)$. However, others found a low correlation between loneliness and social isolation (13-15), suggesting the possibility that social isolation does not always leads to loneliness. One possible explanation for this discrepancy is the fact that social isolation can be defined objectively, whereas loneliness is a subjective feeling that may not necessarily emerge from social isolation. Indeed, this distinction may explain why associations between the two are inconsistently reported across studies (16). Here, we focus on the question of what can be done to mitigate subjective feelings of loneliness that may emerge due to "stay-at-home" regulations widely implemented in many countries.

In fact, quarantine and social isolation during COVID-19 has resulted in novel forms of self-expression - many documented in videos from a variety of countries 
such as Italy, Spain, and Israel. For example, citizens around the world can be seen clapping, singing, and playing musical instruments or applauding healthcare workers - all from their apartment balconies. These "balcony parties" should thus be examined as a tool to break the walls of social isolation and express solidarity with healthcare workers.

Of course, technology offers plenty of platforms for people to stay in touch with each other. Nevertheless, technology-mediated communication lacks the naturalistic element that characterizes everyday face-to-face social interaction. For example, in the latter, interactants inhabit and share the same "physical space". However, online meetings may be social but lack shared physical space (17). From this perspective, balcony parties can be distinguished as social events from alternative technology-mediated forms of gathering (e.g. video chat).

Humans are a social species, attracted to interpersonal interaction and public gatherings. From a spatial attraction perspective, people often seek to share the same physical space and reduce distance between neighbors (18). We may therefore hypothesize that balcony parties offer a possibility to share the same physical space while ensuring social distancing.

Under certain conditions, individuals automatically coordinate their behaviors with those of other participants in social interaction (19-21). Therefore, it is not surprising that during balcony parties individuals align their behaviors with the 
behaviors of their neighbors through hand clapping, singing, or dancing. Notably, this behavioral alignment has been found to elicit reward sensations, encouraging closeness and connectedness (22). Taken together, it is reasonable to assume that balcony parties facilitate naturalistic social interaction. Rewarding sensations associated with this type of interaction may thus act to mitigate the emotional costs of social isolation.

This research focuses on whether balcony parties are perceived and experienced as a tool for mitigating the psychological costs of social isolation. As noted above, the balcony party offers a more real-life and naturalistic form social interaction compared to its technology-mediated counterpart. In addition, it may elicit social alignment and rewarding sensations. Accordingly, we may hypothesize that the more people feel socially isolated the more they will perceive and experience the balcony parties as beneficial in decreasing the costs of social isolation.

\section{Method}

\subsection{Participants}

All persons who were placed in quarantine/social isolation during the coronavirus

outbreaks in Italy and Israel were eligible for participation in this study. Information

on the study and invitations to participate were posted on social media, in Hebrew and Italian. Ethics approval was obtained from the research ethics board of Ariel 
University. The inclusion criteria included an age of more than 18 years and an

agreement to participate in the survey. Participation was rewarded with a coupon

distributed to the 68 student participants from Ariel University (included in the

population of Israeli participants).

\subsection{Tasks, procedures and apparatus}

\subsubsection{Questionnaires}

A web-based survey composed of both multiple choice and short-answer questions was completed by participants in quarantine/social isolation. The questionnaire was divided into two parts. The first part included items on: (1) demographic information, (2) the psychological impact of quarantine, and (3) attitudes towards balcony parties (see section 2.2.2). The second part was filled out only by respondents who participated in at least one balcony party. In this section, (see section 2.2.3), participants were asked to report their experience during the balcony party and similar gatherings that took place before the coronavirus outbreak. It took approximately 7 minutes to complete the first part of the questionnaire and 15 minutes to complete the second.

\subsubsection{Psychological impact of quarantine and social isolation}

The Psychological Impact questionnaire is a self-report measure designed to assess current subjective distress resulting from social isolation and quarantine, composed of five multiple-choice questions. Participants were instructed to read five statements and 
decide how much they either agree or disagree with each, using a Likert rating scale from 1 to 5 . The five statements referred to their feelings while being socially isolated.

They were asked to what degree they felt socially isolated, lonely, distress, longing for face-to-face social or naturalistic interaction with family/friends. The maximum score is 25. The total Psychological Impact of quarantine and social isolation score ranged from 7 to 25 . A correlation analysis was used to examine the relationships between different aspects of social isolation/quarantine. The data concerning the variables related to social isolation/quarantine were not normally distributed, as assessed by a Shapiro-Wilk test. Therefore, the correlation coefficients were calculated using Spearman's correlation. Cronbach's alpha for these five questions was .725.

\subsubsection{Attitude towards the Balcony Party}

To evaluate the attitudes of the general public towards balcony parties, nine multiple choice questions were asked, each with a Likert rating scale from 1 to 5. Participants were asked to rate how much they agreed with each of the following statements: (1) Balcony parties makes me feel united; (2) Balcony parties induce positive feeling; (3) People feel more supported by others; (4) People feel less lonely; (5) Balcony parties help in reducing social isolation; (6) Balcony parties helps distract people from their 
worries; (7) Balcony parties allow people to connect with their neighbors; (8) Balcony

parties are good entertainment; and (9) Balcony parties help in reducing stress and anxiety. The maximum score is 45 . The total attitude score ranged from 9 to 45 . Cronbach's alpha for these nine questions was .946 .

\subsubsection{Beneficial outcomes of the Balcony Party}

To compare the beneficial outcomes of balcony parties and similar pre-outbreak gatherings (e.g. dance party, wedding dancing, singing in a choir, etc.), seven multiple choice questions were asked twice, each with a Likert rating scale from 1 to 5 . One time the questions were asked in relation to beneficial outcomes of participating in balcony parties and one time in relation to pre-outbreak gatherings. Participants were asked to rate how much they agreed with each of the following statements: (1) The gathering makes me feel great! Singing/dancing makes me feel better; (2) The gathering makes us feel united and affiliated; (3) The gathering reduces the feeling of social isolation; (4) The gathering makes me feel less lonely; (5) The gathering makes me feel less anxious and distressed; (6) The gathering makes me feel more connected to my neighborhood; and (7) The gathering helps distract me from worries. The maximum score is 35 for each questionnaire. The total score for experience during the balcony 
party ranged from 11 to 35 , whereas the total score for the pre-outbreak gathering experience ranged from 7 to 35 . Cronbach's alphas for questions on the balcony party was .877 and for pre-outbreak gatherings was .93 .

\subsection{Statistical Analysis}

\subsubsection{Attitude towards the Balcony Party}

As shown in Table 1, we found highly significant positive correlations between all of the five questions aimed at assessing attitude towards the balcony party. We, therefore, calculated an index score for social isolation (sum score of all five items). We then divided our sample into low and high Socially Isolated (SI) according to the median split.

Table 1: Correlation analysis of scales of the questionnaire "Psychological Impact of Quarantine and Social Isolation"

$\begin{array}{llllllll}\text { L } & \text { D } & \text { I } & \text { F-T-F } & \text { F } & \text { D-Q } & \text { A } & \text { C }\end{array}$

\begin{tabular}{|c|c|c|c|c|c|c|c|c|}
\hline $\mathbf{L}$ & 1 & & & & & & & \\
\hline D & $.454^{* *}$ & 1 & & & & & & \\
\hline I & $.311^{* *}$ & $.273^{* *}$ & 1 & & & & & \\
\hline$F-T-F$ & $.262^{* *}$ & $.337^{* \prime}$ & $.334^{* *}$ & 1 & & & & \\
\hline $\mathbf{F}$ & $.193^{* *}$ & $.311^{* \prime}$ & $.304^{* *}$ & $.819^{* *}$ & 1 & & & \\
\hline D-Q & $.190^{* *}$ & $.186^{* *}$ & $.117^{*}$ & -.067 & -.027 & 1 & & \\
\hline Age & .016 & $.137 *$ & -.021 & $-.1 .35^{*}$ & -.077 & $.264^{* \star}$ & 1 & \\
\hline & .037 & $0.132^{*}$ & 0.44 & -.003 & -.055 & $.176^{* *}$ & $.464^{* *}$ & 1 \\
\hline
\end{tabular}

L - "Since the corona outbreak I feel lonely;" D- "Since the corona outbreak I feel distress;" I -" Since the corona outbreak I feel more socially isolated;" F-T-F -" Since the corona outbreak I miss face-to-face social interaction;" F- "Since the corona outbreak I miss naturalistic interaction with my friends/ family". D-Q- " How long have you been in quarantine / isolation/ instructed to stay at home as much as possible?"; A-"What is your age:"; C- "Do you have any children currently living at home with you?" 
To determine whether individual differences in level of social isolation predict attitude towards the balcony parties, we conducted a multivariate analysis of variance (MANOVA), with the two study groups (low SI, high SI) as a between-subject factor. There were nine dependent measures (i.e. nine scores aimed at evaluating the attitude towards the balcony party, see above).

\subsubsection{Beneficial outcomes of participating in parties}

To determine whether individual differences in level of social isolation predict the beneficial outcomes of participating in balcony parties, we conducted 2 (high/low SI) by 2 (type of party) mixed design multivariate analysis of variance (MANOVA), with the two study groups (low SI, high SI) as the between-subject factor, and with type of party (balcony/pre-outbreak parties) as the within-subject factor. There were seven dependent measures (i.e. each of the seven questions aimed at evaluating the beneficial outcomes of the two types of parties, see above).

Pairwise comparisons with Bonferroni corrections were separately conducted for each type of party to determine whether the two groups (low SI, high SI) differed in their mean score of each of the nine measures of beneficial outcomes. 


\subsubsection{Gap between attitude and beneficial outcomes of Balcony Parties}

To determine whether individual differences in level of social isolation predict the gap between attitude towards balcony parties and beneficial outcomes of participating in these parties, we conducted 2 (high/low SI) by 2 (attitude/expectation) mixed design multivariate analysis of variance (MANOVA) with the two study groups (low SI, high SI) as the between-subject factor, and with type of measurements (attitude/expectation towards the balcony parties) as the within-subject factor. Pairwise comparisons with Bonferroni corrections were subsequently conducted for each type of party separately to determine whether differences in the mean score of attitude towards balcony parties and beneficial outcomes of parties.

\section{Results}

The first part of the survey was completed by 303 respondents, who were placed in quarantine or social isolation in Italy $(n=108)$ or Israel $(n=195)$ between March 23th, 2020 and April 2th, 2020. All respondents completed the first part of the survey. As shown in Table 1, the median duration of quarantine was 14 days (interquartile range, 7-20 days). About $81.2 \%$ of respondents were female, $18-73$ years of age, with $33.3 \%$ married and $49.1 \%$ with a college level of education or higher. There were no significant demographic differences between groups except that the group of individuals with high SI had more females. 
The second part of the survey was completed by 207 (68.31\%) respondents who participated at least once in a balcony party. As shown in Table 2, about $86.2 \%$ of respondents were female, with $33.3 \%$ married and $49.1 \%$ with a college level of education or higher. On average, these respondents participated in 2.48 balcony parties.

There were no significant demographic differences between groups except that the group of individuals with high SI reported more days in quarantine.

Table 1: Sample demographic characteristics

\begin{tabular}{|c|c|c|c|c|}
\hline Demographic Data & Total & $\begin{array}{c}\text { Low Level } \\
\mathrm{N}=180\end{array}$ & $\begin{array}{l}\text { High Level } \\
\mathrm{N}=123\end{array}$ & $\begin{array}{l}\text { Statistical } \\
\text { Analyses }\end{array}$ \\
\hline \multicolumn{5}{|l|}{ Parametric measures [mean \pm S.D.] } \\
\hline Age & $34.015 \pm 13.844$ & $33.914 \pm 13.653$ & $34.163 \pm 14.1748$ & $\mathrm{t}(301)=153, \mathrm{p}=.879$ \\
\hline Days in Quarantine & $14.60 \pm 7.839$ & $13.94 \pm 7.506$ & $15.57 \pm 8.248$ & $\mathrm{t}(301)=1778, \mathrm{p}=.076$ \\
\hline \multirow[t]{2}{*}{$\begin{array}{l}\text { Non-parametric measures [Number } \\
(\%)] \quad \text { Gender (male/female)* }\end{array}$} & $\begin{array}{c}57(18.8 \%), 246 \\
\quad(81.2 \%)\end{array}$ & $\begin{array}{c}44(24.4 \%), 136 \\
\quad(44.9 \%)\end{array}$ & $\begin{array}{c}13(10.6 \%), 110 \\
(36.3 \%)\end{array}$ & $\mathrm{X}^{2}=9.211, \mathrm{p}=.002$ \\
\hline & $\begin{array}{c}12(4.0 \%), 142 \\
(46.9 \%), 80(26.4 \%), \\
61(20.1 \%), 8(2.6 \%)\end{array}$ & $\begin{array}{c}6(3.3 \%)^{\prime} 53(29.4 \%), 51(2 \\
8.3 \%), 63(35 \%), 7(4 \%)\end{array}$ & $\begin{array}{c}6(4.9 \%), \\
46(37.4 \%), 27 \\
(21.9 \%), \\
43(40.4 \%), 1 \\
(0.8 \%)\end{array}$ & $\mathrm{X}^{2}=15.528, \mathrm{p}=.214$ \\
\hline $\begin{array}{l}\text { Family Status } \\
\text { (married/single) }\end{array}$ & $\begin{array}{c}101(33.3 \%), 202 \\
\quad(66.7 \%)\end{array}$ & $\begin{array}{c}59(32.8 \%), 121 \\
(67.2 \%)\end{array}$ & $\begin{array}{c}42(34.1 \%), 81 \\
(65.9 \%)\end{array}$ & $\mathrm{X}^{2}=1.491, \mathrm{p}=.475$ \\
\hline $\begin{array}{l}\text { How many children in the } \\
\text { family (no children, } 1 \\
\text { child, } 2-4 \text { children, more } \\
\text { than 4) }\end{array}$ & $\begin{array}{l}225(74.5 \%), 32 \\
(10.6 \%), 44 \\
(14.6 \%), 1(0.3 \%)\end{array}$ & $\begin{array}{c}134(74.9 \%), 17(9.5 \%) \\
28(15.6 \%), 0\end{array}$ & $\begin{array}{l}91(74 \%), 15 \\
(12.2 \%), 16 \\
(13 \%), 1(0.3 \%)\end{array}$ & $\mathrm{X}^{2}=2.311, \mathrm{p}=.510$ \\
\hline Country(Italy/Israel) & $\begin{array}{l}108(35.6) \\
, 195(64,4 \%)\end{array}$ & $64(35.6 \%), 116(64.4 \%)$ & $\begin{array}{l}44(35.8 \%), \\
79(64.2 \%)\end{array}$ & $\mathrm{X}^{2}=.001, \mathrm{p}=.969$ \\
\hline
\end{tabular}


Table 2: Demographic characteristics of Balcony Party participants

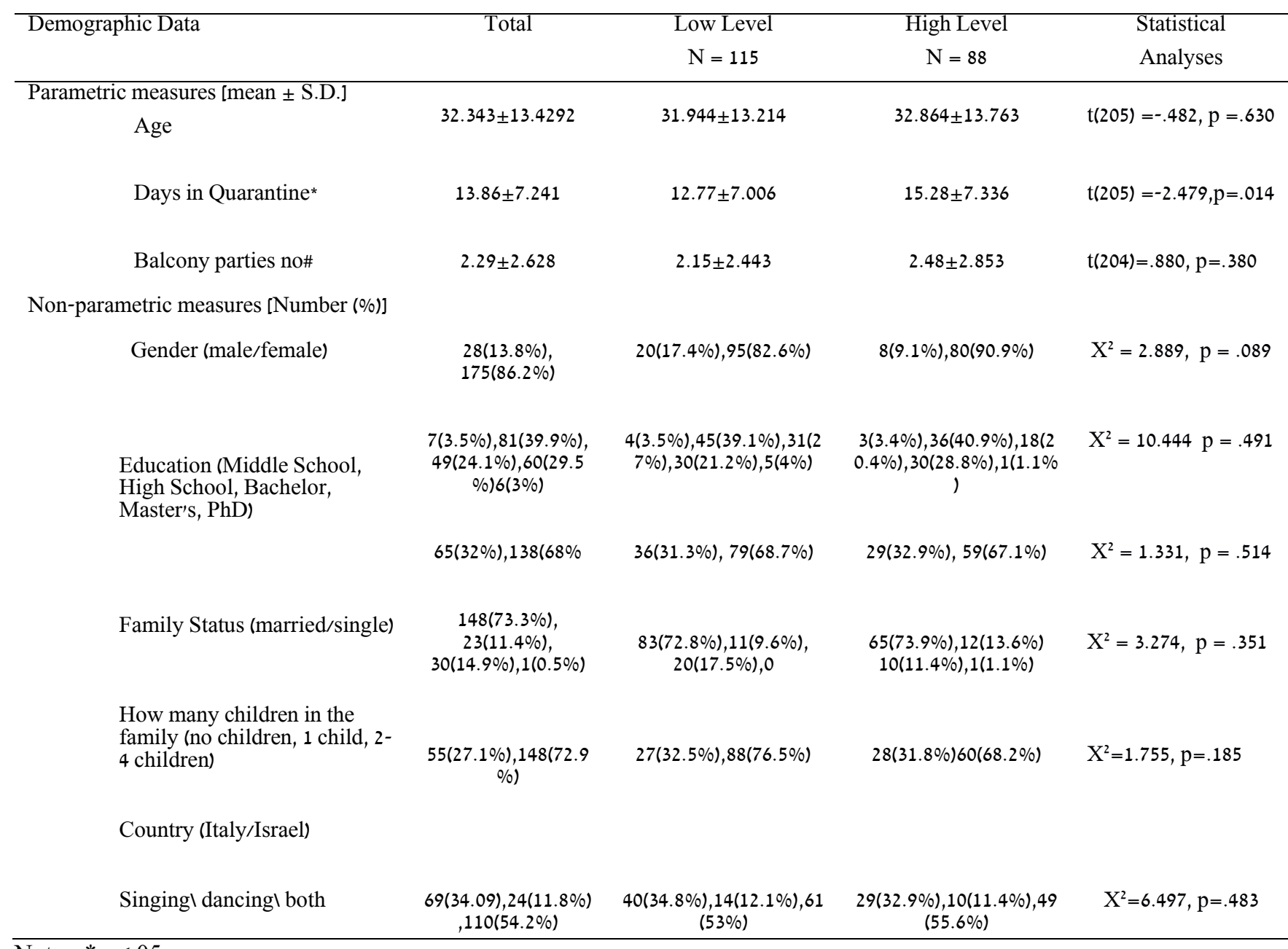

It may be suggested that cultural differences between the two countries (Israel and Italy)

could manifest themselves as a "group" effect in this study. However, as shown in

Tables 1 and 2, there were no significant differences in the proportion of Israelis and

Italians among groups. 


\subsection{Attitude towards the Balcony Party}

The MANOVA revealed a significant group effect $(\mathrm{f}(9,287)=2.667, \mathrm{p}=.005)$,

suggesting an association between level of SI and attitude towards the balcony parties. The level of SI had a statistically significant group effect for balcony parties as inducing feeling of unity $(1,295)=15.807, \mathrm{p}=.000)$, support $(\mathrm{f}(1,295)=8.338, \mathrm{p}=.004)$ and connectedness $(f(1,295)=9.194, p=.003)$, as well as for creating entertainment $(\mathrm{f}(1,295)=8.427, \mathrm{p}=.004)$. However, the group effect was non-significant for the role of balcony parties in reducing feelings of isolation $(\mathrm{f}(1,295)=5.014, \mathrm{p}=.26)$, loneliness $(f(1,295)=2.299, p=.131)$, worries $(f(1,295)=1.691, p=.194)$ and stress $(\mathrm{f}(1,295)=6.644, \mathrm{p}=.010)$ or for evoking positive affect $(\mathrm{f}(1,295)=6.134, \mathrm{p}=.014)$.

Examination of the means indicated that individuals with higher levels of SI had a more positive attitude towards the balcony party (see Figure 1). To examine the effect of group along with the effects of gender, we repeated the same analysis but with the use of gender as another between-participants factor; we obtained the same pattern of results (not presented).

Figure 1: Average scores of attitude towards the Balcony Party divided into low and high SI groups.

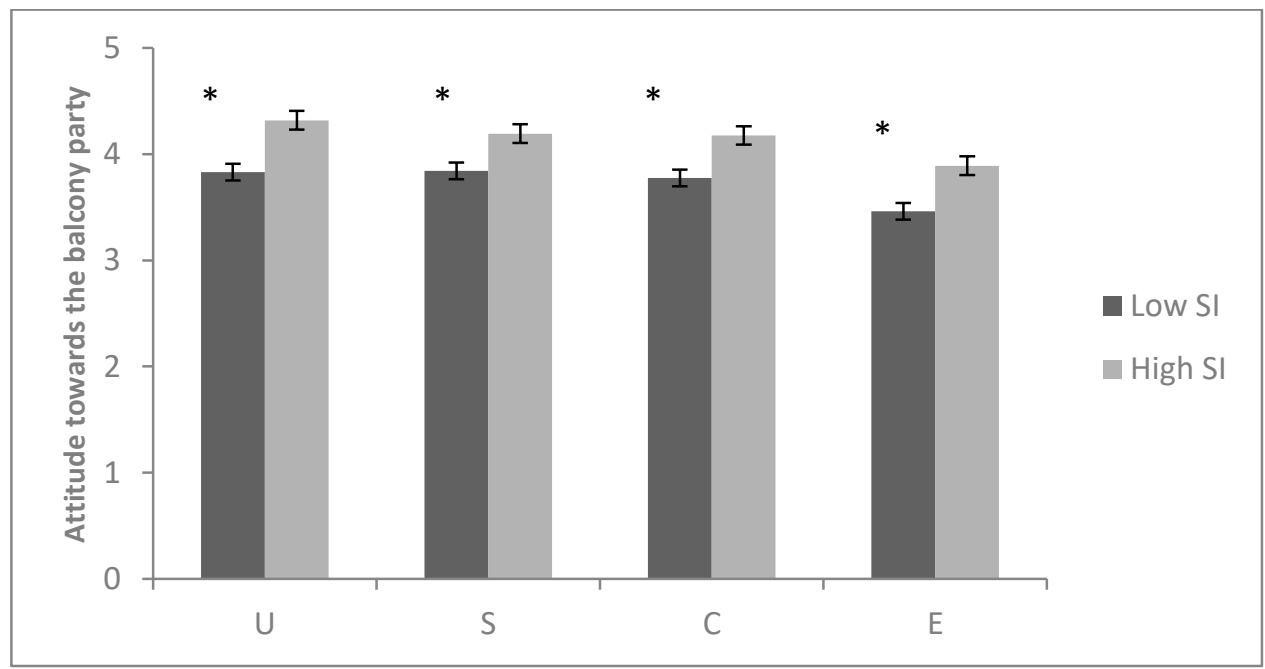

$\mathbf{U}$ - unity, S- support, $\mathbf{C}$ - connectedness, $\mathbf{E}$ - creating entertainment Note $=* p<.05$. The error bars represent the standard error. 


\subsection{The beneficial outcomes of participating in parties}

The MANOVA revealed a significant group effect $(F(7,195)=2.710 p=.011)$ that was qualified by a marginally significant type of measurement (attitude/expectation towards the balcony parties) by group interaction $(F(7,195)=2.019, p=.055)$. Type of measurement by group interaction was found significant for inducing feeling of unity $(\mathrm{F}(1,201)=7.882, \mathrm{p}=.005)$ and for reducing distress $(\mathrm{f}(1,201)=8.475, \mathrm{p}=.004)$, loneliness $(\mathrm{f}(1,201)=11.355, \mathrm{p}=.001)$ and isolation $(\mathrm{f}(1,201)=8.891, \mathrm{p}=.003)$.

However, type of measurement by group interaction was found non-significant for inducing affect $(\mathrm{f}(1,201)=1.720, \mathrm{p}=.191)$, reducing worries $(\mathrm{f}(1,201)=1.398, \mathrm{p}=.238)$ and inducing connectedness $(\mathrm{f}(1,201)=1.807, \mathrm{p}=.180)$. As shown in Table 4, followup pairwise comparisons revealed significant group effects for pre-outbreak gatherings that became non-significant for parties during the outbreak. Examination of the means indicated that the beneficial outcomes associated with the balcony party were lower for the high SI group (unity from 4.18 to 3.93, distress from 4.11 to 3.83, loneliness from 4.27 to 3.98 , and isolation from 4.26 to 4.07 on average). However, the beneficial outcomes for the low SI group were increased (unity from 3.86 to 4.07 , distress from 3.34 to 3.58 , loneliness from 3.77 to 4.03 , and isolation from 3.74 to 4.02 on average). To examine the effect of group along with the effects of number of days 
in quarantine, we repeated the same analysis but with the use of days in quarantine as another covariant and obtained the same pattern of results (not presented).

Table 1. The beneficial outcomes of participating in Balcony Parties vs. preCOVID Parties, according to level of SI

\begin{tabular}{|c|c|c|c|}
\hline & Low SI & High SI & Statistical Analysis \\
\hline \multicolumn{4}{|l|}{ Balcony party: } \\
\hline unity & $4.07 \pm .100$ & $3.932 \pm .115$ & $\mathrm{p}=.367$ \\
\hline reduces isolation & $4.061 \pm .093$ & $4.068 \pm .106$ & $\mathrm{p}=.959$ \\
\hline reduces loneliness & $4.026 \pm .096$ & $3.989 \pm .110$ & $\mathrm{p}=.798$ \\
\hline reduces distress & $3.583 \pm .104$ & $3.830 \pm 119$ & $\mathrm{p}=.121$ \\
\hline \multicolumn{4}{|l|}{ Parties before covid-19 outbreak: } \\
\hline unity* & $3.861 \pm .085$ & $4.182 \pm .097$ & $\mathrm{p}=.014$ \\
\hline reduces isolation* & $3.739 \pm .094$ & $4.261 \pm .108$ & $\mathrm{p}=.000$ \\
\hline reduces loneliness* & $3.765 \pm .088$ & $4.273 \pm .100$ & $\mathrm{p}=.000$ \\
\hline reduces distress* & $3.339 \pm .104$ & $4.114 \pm .119$ & $\mathrm{p}=.000$ \\
\hline
\end{tabular}

Note $=* \mathrm{p}<.05$

\subsection{The gap between attitude and beneficial outcomes of Balcony Parties}

The MANOVA revealed a significant group effect $(F(7,196)=1.149, \mathrm{p}=.000)$. However, there was a significant type of measurement (attitude/expectation towards the balcony parties vs. experience) by group interaction $(F(7,196)=3.624, p=.002)$, suggesting an association between level of SI and differences in the mean score of attitude towards balcony parties as well as beneficial outcomes associated with participating in these parties. Type of measurement by group interaction was found significant for inducing 
feeling of unity with others $(\mathrm{F}(1,202)=14.505, \mathrm{p}=.000)$, but not for inducing other feelings (not presented). Follow-up pairwise comparisons revealed a significant effect for feeling of unity for individuals with high SI ( $p=.001)$, but not for individuals with low SI ( $\mathrm{p}=.373)$. Examination of the means revealed that individuals with high levels of SI expected that the balcony party evoke more of a feeling of unity than it actually did (see Figure 2).

Figure 2: Average scores of attitude and beneficial outcomes of Balcony Parties divided into low and high SI groups.

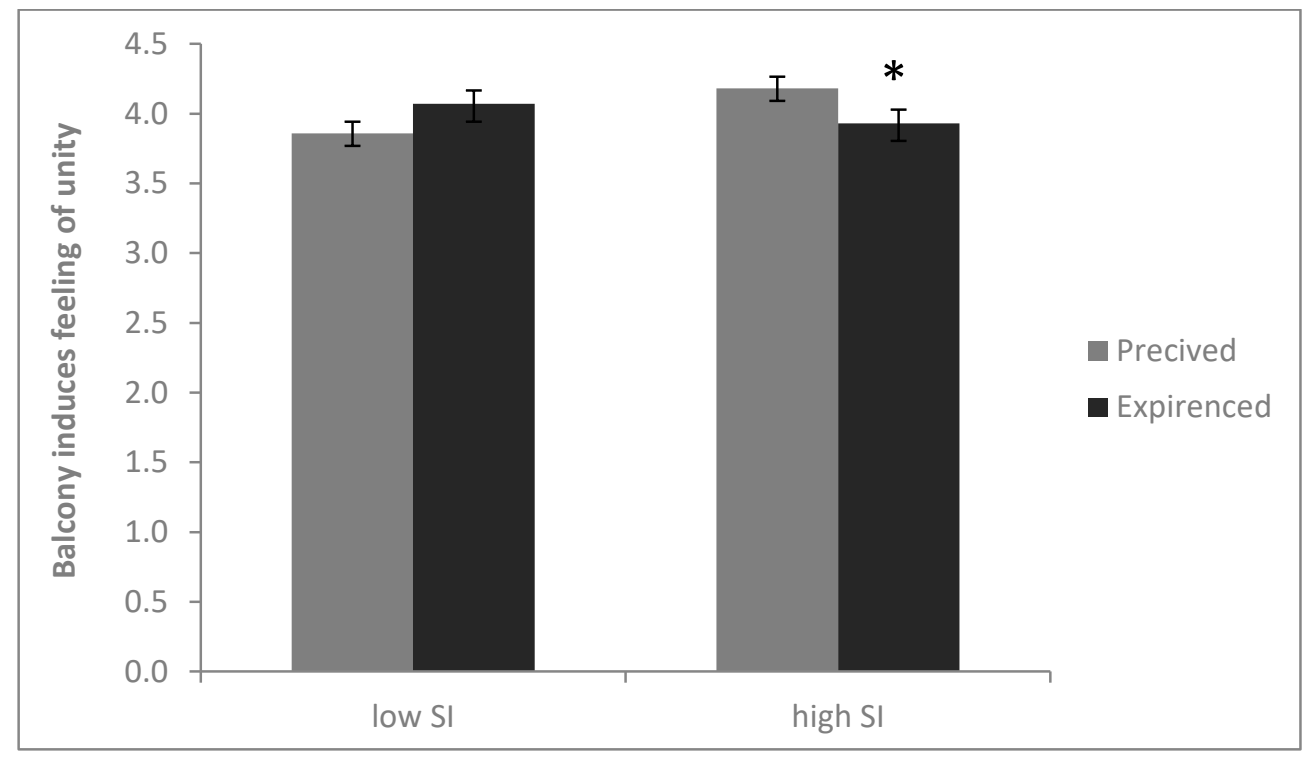




\section{Discussion}

With the new realities of social isolation and quarantine, videos on social media of citizens taking to their balconies to clap, sing, and dance to boost morale are growing increasingly common. To our knowledge, this is the first research to look at balcony parties as a novel way to mitigate the psychological costs of social isolation. While technology-mediated forms of communication are a critical component of modern life, especially during the coronavirus outbreak, they lack basic elements of naturalistic face-to-face social interactions, such as sharing the same physical space (17). Here, we propose the possibility that balcony parties enabled, at least to a certain extent, for more naturalistic social interactions in which different forms of social alignment were induced (19-21). This may explain why these public community balcony gatherings involve neighbors aligning their behavior with each other through hand-clapping, singing, and dancing. Importantly, as these various forms of social alignment are expected to lead to rewarding sensations (22), we speculated that individuals with higher levels of social isolation will embrace this rewarding sensation, thus expressing a more positive attitude towards balcony parties. Our findings confirmed this hypothesis by showing that participants who experienced high levels of social isolation 
during the outbreak of COVID-19 perceived the balcony parties as more beneficial in comparison to those who experienced low levels of social isolation. The opposite pattern was observed when individuals were asked about their participation in these parties. Those with high levels of SI experienced balcony parties as less beneficial than similar events that preceded the COVID-19 outbreak. In contrast, individuals with low levels of SI showed an opposing pattern. Finally, for high SI participants, balcony parties did not satisfy their expectation of creating a feeling of unity with others. However, for their low SI counterparts, balcony parties did meet their expectations. In a changing globalized society, new epidemic outbreaks may result in more periodic episodes of social distancing and quarantine. In turn, this may lead to higher and more widespread levels of social isolation and loneliness (23), a major public health issue which can exert a significant impact on physical and mental wellbeing (24). As such, health professionals need to develop novel solutions to decrease the psychological cost of social isolation. However, coping directly with loneliness and social isolation by strengthening social support or by forming social networks (25) is impeded by the situational factor - the demand to maintain social distance and stay-at-home regulations. Additionally, nostalgia has been suggested as an alternative coping 
strategy to deal with loneliness. Nostalgia refers to an individual's sentimental longing for the past (26). It is considered to be inherent in human nature, resulting from evocation of emotions when reflecting fondly on positive past memories (27). As noted earlier, our findings show that those with high levels of SI reflected on preoutbreak gatherings in the past as more beneficial than the balcony parties of the present. Moreover, this tendency was not evident among individuals with low levels of social isolation, This may suggest that higher levels of social isolation are associated with increased tendency to augment subjective perceptions of social support by drawing on nostalgic memories. In other words, individuals with high levels of SI may employ nostalgia as a psychological resource, and this was manifested in their tendency to reflect on pre-outbreak gatherings of the past as more beneficial than the balcony parties of the present. This interpretation, however, requires caution, with further research needed to rule out other potential explanations such as differences in clinical characteristics between the two groups. Resilience, which refers to the ability to recover from shock, insult, or disturbance (Garmezy, 1991), is also of great relevance for examining the psychological cost of social isolation during the COVID-19 outbreak. Interestingly, it 
has been found that highly resilient individuals are most likely to recruit nostalgia in response to loneliness (27). While our findings suggest the possibility that nostalgia acts as a strategy to respond to emotional challenges associated with social isolation, the question of whether nostalgia can boost levels of resilience to the cost of social isolation deserves to be investigated.

Our findings reveal a gap between how individuals perceived the balcony parties and how they actually experience it. This suggests the possibility that the expectation for rewarding sensations associated with participating in balcony parties was not fulfilled. Indeed, a within-subjects approach revealed that individuals with high levels of SI expected the balcony parties to induce more feeling of unity with others than they actually experienced. Importantly, the discrepancy between expectation and actual experience was not observed for individuals with low levels of SI - their experience of feeling united with others did meet their expectations. The discrepancy between how the balcony parties were perceived and how they were actually experienced may be interpreted in view of the predictive coding perspective(28). In this framework, the brain is essentially a "prediction machine" with the ultimate goal of "prediction error" minimization; that is, the discrepancy between incoming information and generated 
predictions (29). As such, it is possible that the experience of individuals with higher SI during the balcony parties was different from their experiential prediction, with this gap constituting a "prediction error". Since prediction error is experienced as an unpleasant state, the brain constantly strives to minimize this error (30). For this, there are two options: 1) through action to change the environment to fulfill expectations and 2) by optimizing these expectations for better sensation matching. Achieving alignment with others has been argued to reduce prediction error by making the environment more predictable $(29,30)$. Previous work has shown that social isolation can modulate the way in which individuals perceive and mirror the expressions and actions of others (32). Hence, it is reasonable to propose that those with high levels of social isolation SI suffer from deficiencies in their capacity to achieve alignment during the balcony parties, with this constituting a prediction error.

It should be noted that this study has several limitations. First, although the number of respondents was relatively high, it is possible that it is not a representative sample of the entire group of people under quarantine, especially since respondents were mostly women. Second, respondents required access to a computer to respond, which suggests a self-selection effect may have occurred. More specifically, it suggests 
that those who agreed to participate may have been more educated, younger and had higher socioeconomic status than the overall group who were quarantined (in Israel and in Italy). Third, all data was derived from self-report questionnaires which is vulnerable to a recall bias. In this context, it is important to mention that we strived to obtain as much information about the adverse effects of quarantine as close to the event as possible so as to eliminate recall bias. Hence, the project was initiated when concerns about COVIID-19 were still a part of daily life in both in Israel and Italy. Finally, the cross-sectional nature of this study limits our ability to determine any causality in the results.

In conclusion, due to globalization and urban population density, social isolation may emerge as a prominent new reality in an age of pandemics. The costs of social distancing and quarantine thus need to be closely evaluated in the context of psychological suffering. As such, balcony parties constitute a novel counter-measure to provide a measure of naturalistic face-to-face social interaction, thereby mitigating the psychological costs of social isolation. Our findings suggest that its role is dependent on participant level of SI. Balcony parties benefited individuals with lower SI, whereas the opposite was observed for high SI participants. Earlier research has linked feelings 
of closeness with neighbors and intention to take a vaccine or wash hands more frequently during a pandemic (33). Future empirical efforts should consider the possibility that participating in balcony parties is beneficial for those with low levels of SI, not only to reduce the emotional cost of social isolation but also to increase precautionary habits needed during the coronavirus, in particular washing hands.

As a final note, in earlier studies exposure to a virus was found to be necessary, but not sufficient, to cause illness. Notably, chronic stress and social isolation, among other psychological factors, may partly determine development of an acute infectious respiratory illness (34). In line with this, our findings on assessing mitigation cost strategies of social isolation may be valuable in reducing the risk of developing COVID-19. 


\section{References}

1. Jebril N. World Health Organization Declared a Pandemic Public Health Menace: A Systematic Review of the Coronavirus Disease 2019 "COVID-19", up to 26th March 2020 by Nadia Jebril :: SSRN [Internet]. Available at SSRN 3566298. [cited 2020 Apr 27]. Available from: https://papers.ssrn.com/sol3/papers.cfm?abstract_id=3566298

2. Goh KT, Cutter J, Heng BH, Ma S, Koh BKW, Kwok C, et al. Epidemiology and control of SARS in Singapore. Ann Acad Med Singapore. 2006 May;35(5):301-16.

3. Wilder-Smith A, Freedman DO. Isolation, quarantine, social distancing and community containment: pivotal role for old-style public health measures in the novel coronavirus (2019-nCoV) outbreak. 2020 [cited 2020 Apr 28]; Available from: https://academic.oup.com/jtm/article-abstract/27/2/taaa020/5735321

4. Cetron M, Landwirth J. Public health and ethical considerations in planning for quarantine. Vol. 78, The Yale journal of biology and medicine. Yale Journal of Biology and Medicine; 2005. p. 329-34.

5. Brooks SK, Webster RK, Smith LE, Woodland L, Wessely S, Greenberg N, et al. The psychological impact of quarantine and how to reduce it: rapid review of the evidence. Vol. 395, The Lancet. Lancet Publishing Group; 2020. p. 912-20.

6. Wang C, Pan R, Wan X, Tan Y, Xu L, Ho CS, et al. Immediate Psychological Responses and Associated Factors during the Initial Stage of the 2019 Coronavirus Disease (COVID-19) Epidemic among the General Population in China. Int J Environ Res Public Health [Internet]. 2020 Mar 6 [cited 2020 May 26];17(5):1729. Available from: https://www.mdpi.com/1660-4601/17/5/1729

7. Victor CR, Scambler SJ, Bowling A, Bond J. The prevalence of, and risk factors for, loneliness in later life: A survey of older people in Great Britain. Ageing Soc. 2005;25(3):357-75.

8. Weiss RS. Loneliness: the experience of emotional and social isolation. MIT Press; 1974. 236 p.

9. Archibald FS, Bartholomew K, Marx R. Loneliness in Early Adolescence: A Test of the Cognitive Discrepancy Model of Loneliness. Personal Soc Psychol Bull. 1995 Mar;21(3):296-301.

10. Leigh-Hunt N, Bagguley D, Bash K, Turner V, Turnbull S, Valtorta N, et al. An overview of systematic reviews on the public health consequences of social isolation and loneliness. Vol. 152, Public Health. Elsevier B.V.; 2017. p. 15771.

11. Cacioppo JT, Hawkley LC. Perceived social isolation and cognition. Vol. 13, Trends in Cognitive Sciences. Elsevier Current Trends; 2009. p. 447-54.

12. Peplau LA, Perlman D. Loneliness : a sourcebook of current theory, research, and therapy. New York: Wiley; 1982. 430 p.

13. Cornwell EY, Waite LJ. Social disconnectedness, perceived isolation, and health among older adults. J Health Soc Behav. 2009 Mar;50(1):31-48.

14. Coyle CE, Dugan E. Social isolation, loneliness and health among older adults. J Aging Health. 2012 Dec;24(8):1346-63.

15. Steptoe A, Shankar A, Demakakos P, Wardle J. Social isolation, loneliness, and all-cause mortality in older men and women. Proc Natl Acad Sci U S A. 2013 Apr;110(15):5797-801.

16. Tanskanen J, Anttila T. A Prospective Study of Social Isolation, Loneliness, and 
Mortality in Finland. Am J Public Health. 2016 Nov;106(11):2042-8.

17. Blanchard AL, McBride A. Putting the "Group" in Group Meetings: Entitativity in Face-to-Face and Online Meetings. In Emerald Publishing Limited; 2020. p. 71-92.

18. Belz M, Pyritz LW, Boos M. Spontaneous flocking in human groups. Behav Processes. 2013 Jan;92:6-14.

19. Schilbach L. Towards a second-person neuropsychiatry. Philos Trans R Soc B Biol Sci [Internet]. 2016 Jan 19 [cited 2019 May 29];371(1686):20150081. Available from: http://rstb.royalsocietypublishing.org/lookup/doi/10.1098/rstb.2015.0081

20. Gvirts HZ, Perlmutter R. What Guides Us to Neurally and Behaviorally Align With Anyone Specific? A Neurobiological Model Based on fNIRS Hyperscanning Studies. Neurosci [Internet]. 2019 Jul 11 [cited 2019 Sep 14];107385841986191. Available from: http://journals.sagepub.com/doi/10.1177/1073858419861912

21. Gvirts Probolovski HZ. Commentary: Using second-person neuroscience to elucidate the mechanisms of reciprocal social interaction. Vol. 14, Frontiers in Behavioral Neuroscience. Frontiers Media S.A.; 2020.

22. Shamay-Tsoory SG, Saporta N, Marton-Alper IZ, Gvirts HZ. Herding Brains: A Core Neural Mechanism for Social Alignment. Vol. 23, Trends in Cognitive Sciences. Elsevier Ltd; 2019. p. 174-86.

23. Goethals L, Barth N, Guyot J, Hupin D, Celarier T, Bongue B. Impact of home quarantine on physical activity among older adults living at home during the COVID-19 pandemic: Qualitative interview study. J Med Internet Res. 2020 May 1;22(5):e19007.

24. Jeste D V., Lee EE, Cacioppo S. Battling the Modern Behavioral Epidemic of Loneliness: Suggestions for Research and Interventions. JAMA Psychiatry. American Medical Association; 2020.

25. Asher SR, Paquette JA. Loneliness and Peer Relations in Childhood. Curr Dir Psychol Sci [Internet]. 2003 Jun 23 [cited 2020 May 27];12(3):75-8. Available from: http://journals.sagepub.com/doi/10.1111/1467-8721.01233

26. Pearsall J, Hanks P. The new Oxford dictionary of English. 1998;1266.

27. Zhou X, Sedikides C, Wildschut T, Gao D-G. Counteracting Loneliness On the Restorative Function of Nostalgia. 2008.

28. Palmer CJ, Lawson RP, Hohwy J. Bayesian approaches to autism: Towards volatility, action, and behavior. Psychol Bull [Internet]. 2017 May 1 [cited 2020 Jun 24];143(5):521-42. Available from: https://psycnet.apa.org/journals/bul/143/5/521

29. Friston K. The free-energy principle: a unified brain theory? Nat Rev Neurosci [Internet]. 2010 Feb 13 [cited 2018 May 5];11(2):127-38. Available from: http://www.nature.com/doifinder/10.1038/nrn2787

30. Shamay-Tsoory SG, Saporta N, Marton-Alper IZ, Gvirts HZ. Herding Brains: A Core Neural Mechanism for Social Alignment. Trends Cogn Sci [Internet]. 2019 Jan 21 [cited 2019 Feb 15];23(3):174-86. Available from: http://www.ncbi.nlm.nih.gov/pubmed/30679099

31. Bolis D, Schilbach L. Beyond one Bayesian brain: Modeling intra-and interpersonal processes during social interaction: Commentary on "mentalizing homeostasis: The social origins of interoceptive inference" by Fotopoulou \& Tsakiris. Vol. 19, Neuropsychoanalysis. Routledge; 2017. p. 35-8.

32. Ong AD, Uchino BN, Wethington E. Loneliness and Health in Older Adults: A 
Mini-Review and Synthesis. Gerontology [Internet]. 2016 Jun 15 [cited 2020

Apr 20];62(4):443-9.

Available

from:

https://www.karger.com/Article/FullText/441651

33. Miao Y-Y, Huang J-H. Prevalence and associated psychosocial factors of increased hand hygiene practice during the influenza A/H1N1 pandemic: findings and prevention implications from a national survey in Taiwan. Trop Med Int Heal. 2012 May;17(5):604-12.

34. Cohen S, Tyrrell DA j., Smith AP. Psychological stress and susceptibility to the common cold. N Engl J Med. 1991 Aug 29;325(9):606-12. 